\title{
Managers as Agents Without Principals: An Empirical Examination of Agency and Constituency Perspectives
}

\author{
Huseyin Leblebici \\ University of Illinois \\ Avi Fiegenbaum \\ University of Michigan
}

\begin{abstract}
This study empirically investigated the propositions generated from agency and constituency perspectives about the nature of the managerial role. The managerial role was conceptualized as an integral part of the existing outcome interdependencies and power relations among a set of constituencies. By using time-series data on $160 \mathrm{com}$ panies in 10 manufacturing industries and performing three-stage least squares (3SLS) analyses, it was found that both competitive and symbiotic outcome interdependencies exist among the constituencies of organizations, and that these interdependencies are related to the long-term average outcomes of these constituencies. The implications of these findings for the symbolic role of managers is discussed.
\end{abstract}

Providing an answer to the question, "What is the role of a manager?" interests both theoreticians and practitioners. For theoreticians, it is a necessary first step in understanding the nature of the firm. For practitioners, it is a prerequisite to having a meaningful measure of managerial effectiveness and to develop successful incentive mechanisms for managers.

Traditionally, both in economics and in finance, managerial role is defined essentially as that of an agent. Managers, as the agents of the principal owners or the residual claimants, operate within the contingent limitations of property rights, agency costs, and managerial contracts. In organization theory, as well as in business policy, the role of the manager is framed within the assumption that organizations are coalitions of interest groups with different and often conflicting demands and expectations. Within this framework, the behavior of the manager is explained in terms of the power distribution among the coalition members who represent the constituencies of the organization.

This article compares these two alternative approaches with regard to their the-

Address all correspondence to Huseyin Leblebici, Department of Business Administration, 350 Commerce Building (West), 1206 South Sixth Street, University of Illinois, Champaign, IL 61820.

Copyright 1986 by the Southern Management Association 0149-2063/86/\$2.00. 
oretical implications and describes tests of hypotheses based on these implications. An attempt is also made to integrate these alternative approaches by identifying their commonalities.

\section{Background}

Since the first publication of The Modern Corporation and Private Property by Berle and Means (1932), economists have been interested in the role of managers. The introduction of the manager into the economic scene of the firm required modifications in the classical model of the firm in which the owner-manager single-mindedly operated the firm to maximize profits. The separation of security ownership and control, typical in large corporations, produced two distinct approaches to management incentive problems - problems which arise when decision making in a firm is under the control of managers who are not the firm's major security holders. One distinct approach has focused on the motivation of managers and required modifying the classical assumptions of "the economic man." Behavioral or managerial theories of the firm developed by Baumol (1959), Simon (1959), and Cyert and March (1963) are classic examples of this approach.

More recently, a second approach, developed by Alchian and Demsetz (1972) and Jensen and Meckling (1976), defined the management incentive problem in terms of agency costs and property rights. This new analytical formulation of the relationship among owners and managers (Fama \& Jensen, 1983) focused on two interrelated questions: (a) If the separation of ownership and control produces incentive problems in terms of monitoring costs, information asymmetry, and conflicting preferences, is there an optimum ownership structure within which these costs can be minimized? (b) Given that the existence and survival of corporate form indicates that it is an efficient form, what structural characteristics are responsible for its efficiency and therefore for its survival?

These questions and the search for answers currently represent a distinct stream of literature in finance and economics which constitutes agency/ownership structure theory. Within this theoretical perspective, contrary to the behavioral theories of the firm, the classical assumptions of economic behavior are not rejected; what is rejected is the classical definition of the firm. As Fama (1980) has argued, the firm can be seen as a nexus of contracts among factors of production where each factor is motivated by its self-interest.

Organization theory, particularly the resource dependency perspective (Pfeffer \& Salancik, 1978), presents an alternative argument on the nature and the role of managers in organizations. It starts with the premise that every organization, in order to be viable, must take into consideration the demands of different constituencies with conflicting interests. Constituencies of any organization are continually evaluating their relationships with the organization on the basis of different criteria and deciding whether to remain in the coalition or to alter their relationship with the organization. The coalition view of organizations assumes that there will be conflicts over objectives rather than consensus over one or a few organizational goals (Pfeffer, 1978). Some empirical evidence supports the view that organizations serve many constituencies with conflicting criteria. Friedlander and Pickle (1968), for instance, have shown that organizational effectiveness, 
when evaluated from the perspectives of the owners, employees, creditors, suppliers, customers, or the government, is a function of these different constituencies' assessment of organizational performance.

\section{Commonalities and Differences Between Perspectives}

One of the basic questions posed by these perspectives is how to characterize the role of the manager with respect to a set of parties who are involved in the formation and continuation of an organization. The common denominator in all these perspectives is that managerial role is defined with respect to a group of participants. Whether they are called the factors of production, or the constituencies of the dominant coalition, the relationships among these participants and managers determine the role, behavior, and strategic decisions of the managers. What distinguishes these two distinct frameworks is their approach to the question of who should be included in this set of participants and what the relationship between managers and the members of the set is. In the behavioral theory of the firm and in the finance literature, the set basically includes residual claimants and debtholders. The relationship between these participants and managers is defined within an agency framework. In organization theory, particularly in resource dependency models, the set includes all participants within the task environment of the organization. And the relationship between managers and the members of the set is defined within a constituency framework.

In analyzing the relationships among these parties, empirical research within each framework has concentrated on certain specific relationships among different participants, management, and the performance of the organization. Within agency theory, one of the most commonly investigated empirical problems has been the relationship between types of ownership and organizational performance. The empirical evidence so far, however, is very mixed. Researchers have found the separation of ownership to be associated with a low return on investment (Kamerschen, 1968; Palmer, 1973), a high return on investment (Ware, 1975), or no strong relationship (Holl, 1975; McKean \& Kania, 1978; Sorensen, 1974); or have identified differences in strategic choices and management processes between privately and publicly held companies (Trostel \& Nichols, 1982).

The empirical research questions asked within the constituency framework are much more extensive. They range from questions concerning mergers (Pate, 1969) and joint ventures (Pfeffer, 1972) to the composition of boards of directors. The main theoretical concern of most research in this area is to provide evidence that organizations are other-directed, involving constant rearrangement of interdependencies for organizational autonomy and discretion (Aharoni, Maimon, \& Seger, 1978; Freeman, 1984). In other words, interdependence, which characterizes the relationships among different interest groups, is critical for understanding the behavior and strategies of managers.

When compared, these approaches make the following basic predictions about the relationships among different participants. Agency theory predicts that there is an existing interdependency between stockholders and bondholders, and that their efficient arrangement or composition will produce successful outcomes for the organization as a whole. More specifically, there exists a simultaneous relationship between the outcomes of bondholders and stockholders, and, compared 
to other interest groups such as customers or suppliers, one should observe relatively stronger simultaneous relationship between bondholders and stockholders in terms of outcome interdependencies.

By contrast, the constituency framework predicts that different constituencies represented in the coalition have different degrees of power resulting from the outcome interdependencies among them. Specifically, the powerful members of the coalition will receive a proportionately greater share of organizational outcomes because they have greater influence on the outcomes of the less powerful members. According to the constituency framework, the greater the outcome control power of a constituency, the greater the outcomes received by that constituency.

\section{Data and Method}

In order to test these propositions, it was necessary to resolve three interrelated methodological problems. First, a set of critical constituencies and a set of relevant performance measures associated with the outcomes received by them had to be identified. Second, it was necessary to identify the simultaneous relationships among these outcomes which could provide information about the existing interdependencies among these interest groups as well as their outcome control powers. In other words, a set of correlations among the constituencies' outcomes would not have been sufficient to measure the independent influence of each constituency's outcomes on the others. We also had to consider the influence of the environment on these outcomes in the calculation of outcome interdependencies. Third, it was necessary to develop a measure of outcome control power based on these outcome interdependencies.

These methodological problems were resolved by implementing a two-stage strategy. The outcome interdependencies among different interest groups were measured at the industry level by using a pooling time-series cross-section data analysis. At this level, company-specific time-series data were used. For the actual hypothesis testing, on the other hand, all the analyses were done at the interindustry level by using the estimations derived from the three-stage least squares (3SLS) analyses performed at the industry level.

\section{Sample}

Because of the methodological issues discussed above, the sampling was also done in two stages. First, a set of manufacturing industries was randomly selected for which time-series company data were available from Standard \& Poor's Compustat tapes. Second, within each industry, eight years of financial data on each company included in the Compustat files were collected. Some of these industries, which were included in the original sample, were later deleted because of extensive missing information. The final sample included 10 manufacturing industries. Within each industry sampled, the average number of companies was 16 . The final sample contained 160 companies in 10 industries for the period of 1972-1980.

\section{Measures}

Critical constituencies and their outcomes. The set of all constituencies of an organization can include parties ranging from stockholders to government agen- 
cies and special interest groups, but for the purpose of this study only those groups which represent the primary task environment of the organization were selected-stockholders, bondholders, customers, and other short-term interest groups such as suppliers, short-term creditors, and employees. It was assumed that these different constituencies, because of their unique relationship with the organization, are interested in different economic aspects of a firm's operations and performance.

The literature on financial analysis indicates that different users of financial accounting information utilize different aspects of a firm's financial performance. For instance, investors are mainly concerned with profitability, and lenders with solvency information (Lev, 1974). In other words, it is possible to identify certain financial information, particularly financial ratios, which are relevant measures of the firm's performance with respect to different interest groups. This does not mean, however, that these groups are directly responsible for and have control over these outcomes. Financial accounting information and financial ratios are the outcomes of managerial decision making. They represent how the limited resources of the firm are allocated to different constituencies. Furthermore, these decisions are the outcomes of managers' strategic choices, their perception of the constituencies' importance, and noncontrollable environmental factors.

Empirical research on financial ratios has produced some important findings which were useful for our purpose. Different classifications of financial ratios indicate that there are some major independent classes of these ratios. For instance, when the most commonly used financial ratios are factor analyzed, there are some consistent empirical similarities among alternative financial ratios (Cheng \& Skimenda, 1981; Gupta \& Huefner, 1972; Pinches, Eubank, Mingo, \& Caruthers, 1975; Pinches, Mingo, \& Caruthers, 1973). The major implication of these findings is that even though these ratios utilize a common data base of financial information, they produce approximately seven independent factors. Furthermore, most of the common factors found in these empirical studies correspond to the theoretical classification of financial ratios, which are oriented to the needs of outside users, in our case the major constituencies.

Based on this theoretical and empirical knowledge, four classes of outcome measures were identified - return on equity, financial leverage, short-term liquidity, and turnover ratios. Each of these was then matched with different groups of constituencies: return on equity for residual claimants, financial leverage for bondholders, short-term liquidity for suppliers, employees, and short-term creditors, and turnover for customers. Within each class of financial ratios, a specific ratio was selected by using two criteria: whether or not it was most commonly used in empirical studies, and whether or not it had high factor loading in those empirical studies. The following four ratios were selected as representing how the firm's limited resources are allocated among four groups of constituencies: return on equity, debt to total assets, quick ratio, and sales to toal assets. These ratios were the four outcome variables used in the study.

Outcome interdependencies. The outcome interdependencies among various interest groups are not directly observable but must be estimated within a dynamic model. If we view alternative measures of performance as outcomes of dif- 
ferent constituencies, the relationships among these performance measures within a given industry can be expressed in a simultaneous system of equations that explicitly recognizes the interdependencies among these outcomes. Using Ackoff's (1970) formulation of strategic management, we describe the performance of an organization as a function of both controllable management decision variables and noncontrollable environmental variables.

$$
\begin{gathered}
\text { Performance }=f(\text { Controllable decision variables, non- } \\
\text { controllable environmental variables })
\end{gathered}
$$

Given the simultaneous and dynamic nature of the relationship between different measures of performance, the general model for a given industry can be expressed as follows:

$$
\begin{aligned}
& P_{1}=f\left(P_{2}, \ldots, P_{n}, C_{1}, N C_{1}\right) \\
& \cdot \\
& \cdot \\
& P_{n}=f\left(P_{1}, \ldots, P_{n-1}, C_{n}, N C_{n}\right) \\
& P_{i}=\text { performance measure with respect to } i \text { th constitu- } \\
& \text { ency; } \\
& C_{i}=\text { set of controllable variables directly related with } \\
& \text { the } i \text { th performance; } \\
& N C_{i}=\text { set of noncontrollable environmental variables di- } \\
& \text { rectly related to the } i \text { th performance measure; } \\
& n=\text { number of constituency groups. }
\end{aligned}
$$

An important advantage of the model is that it explicitly takes into account both managerial strategies and noncontrollable environmental factors. Controllable decision variables reflect the cumulative impact of managerial decisions on specific outcomes of different interest groups. Noncontrollable environmental variables represent the industry-specific conditions which are beyond direct management control. Because industries differ in the way strategies are played as well as in environmental conditions (Porter, 1980), it was necessary to measure outcome interdependencies at the industry level.

Table 1 presents the model specification and the list of variables included in the model. The independent variables were selected according to three criteria: (a) their significance based on their use in the theoretical and empirical literature, (b) availability of time-series data, and (c) measures of each variable at the interval or ratio scale level. The selection of both controllable and noncontrollable independent variables was based on previous literature (Hurdle, 1974: Martin, 1976; Schendel \& Patton, 1978). Three-stage least-squares (3SLS) was selected as an appropriate method for estimating the parameters in the model.

The results of the 3SLS analysis for each industry, especially the parameters estimated for $P_{i} \mathrm{~s}$, represent the measures of outcome interdependencies among different interest groups. Table 2 presents the standardized $b$ values of each performance measure as specified in the model for each of the 10 industries included 
Table 1

Model Specification and the

List of Variables Used in the Simultaneous Equations for Each Industry in the Sample

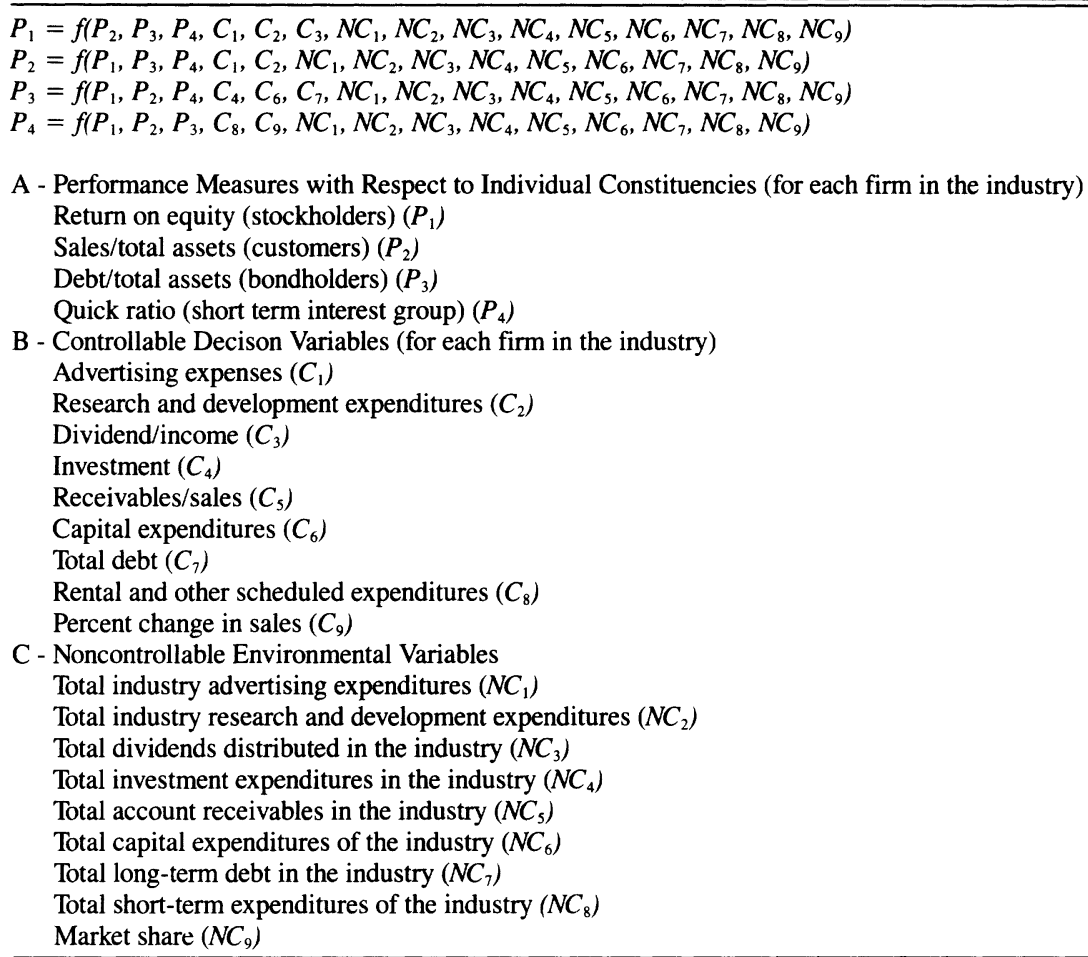

in the sample. Each column in these square matrices shows how a given performance variable is influenced by the three other constituencies' outcomes. Each row in the matrix shows how a given constituency's outcome influences the outcomes of the others. Numbers in these matrices are the standardized $b$ coefficients $(p<.10)$. Nonsignificant relations are indicated by .00 .

Within the framework of the model developed, the outcome control power of a constituency can be measured in several ways. If we assume that standardized $b$ coefficients indicate the degree of influence of one constituency on others' outcomes, the sum of absolute values of standardized $b s$ for each row in Table 2 represents the aggregate outcome control power of each constituency $\left(\sum_{i=1}^{3}\left|\beta_{i}\right|\right)$. The sum of each column, on the other hand, represents the aggregate outcome dependency of each constituency $\left(\sum_{j=1}^{3}|\beta . j|\right)$. Aggregate outcome control power and outcome dependency were calculated by taking the absolute values of $\beta_{i j}$, because we were interested only in the degrees of outcome control, not in their signs. By utilizing these two aggregate measures, a third measure of outcome control power was also calculated. The net outcome control power of each constituency was measured by subtracting the aggregate outcome dependency from the aggregate outcome control power $\left(\Sigma\left|\beta_{i} \cdot\right|-\Sigma \mid \beta_{. j}\right)$. We reiterate that what is 


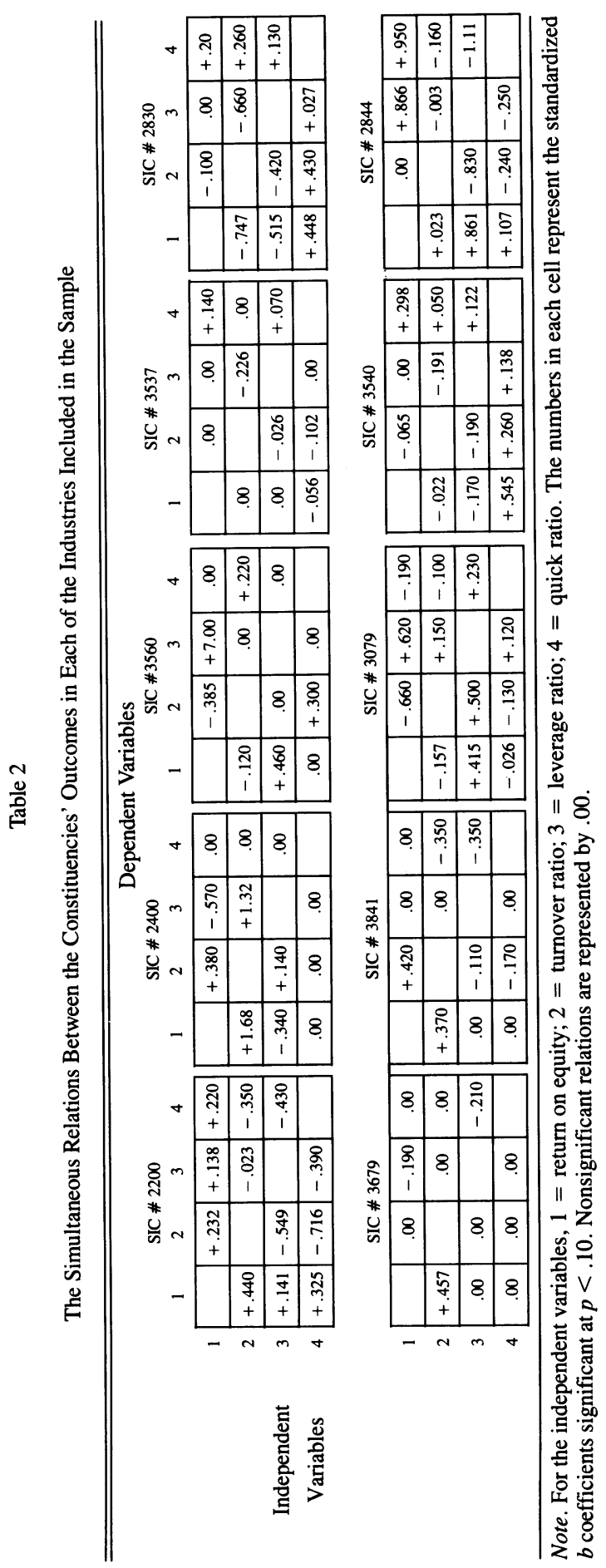


meant by outcome control power is not an actual control of a given constituency on the decisions of managers, but is the outcome of managerial decision making under uncertainty. As such it is only a surrogate measure.

\section{Analysis and Results}

\section{The Nature of Outcome Interdependencies}

The results of the 3SLS analyses of individual industries show that on the average the four sets of simultaneous equations collectively explained $89 \%$ of the variance (the mean weighted $R^{2}=.89$ ). These results suggest that the initial model for the first stage of the analysis is reasonable. Because the exact meaning of the weighted $R^{2}$ is controversial, however, it should be emphasized that the initial model is only reasonable rather than definite. For the rest of the analysis, the critical issue is the nature of interdependencies among performance outcomes of the four interest groups as estimated by the 3SLS analyses.

As Table 2 indicates, there exist simultaneous relations between not only the residual claimants and the bondholders but among all the interest groups. Furthermore, the outcome interdependencies are competitive as well as symbiotic in half of the cases. In only $10 \%$ of the cases are the relationships unidirectional, and these are randomly distributed. These results provide some initial support for the resource dependency perspective that outcome interdependencies, both competitive and symbiotic, exist among the major interest groups represented in the dominant coalition of organizations (Pfeffer \& Salancik, 1978).

In order to test the first proposition, correlations between the standardized $b$ coefficients for different constituencies were calculated. The argument was that if the independent influence of two performance measures on each other (i.e., $b_{i j}$ and $b_{j i}$ ) were highly correlated, there would exist a high degree of outcome interdependency between these two groups of constituencies. Even though such a correlation cannot distinguish between symbiotic and competitive interdependencies, it can indicate the magnitude of the outcome interdependency between constituencies. As shown in Table 3, results indicate that there are two sets of constituencies with a high degree of outcome interdependency. In one group, the residual claimants and the bondholders exert an equal degree of influence on each other's outcomes. In the other group, a similar relationship exists between the customers and the short-term interest. These groups represent two distinct classes of constituencies in terms of outcome interdependencies, because none of the other correlations in the table are significant.

These findings also indicate that the theoretical relationships articulated in the

Table 3

Correlations Between the Constituencies' Degrees of Outcome Control $(N=10)$

\begin{tabular}{lccc}
\hline \hline & $\begin{array}{c}\text { Residual } \\
\text { Claimants }\end{array}$ & Customers & Bondholders \\
\hline Customers & .27 & & \\
Bondholders & $.86^{* *}$ & .42 & .41 \\
Short-term Interest & .33 & $.88^{* *}$ & .41 \\
\hline
\end{tabular}

${ }^{*} p<.05 .{ }^{* * p}<.01$. 
financial literature between stockholders and bondholders is relevant. Even though there exists some degree of outcome interdependency among all interest groups, these two constituencies represent a critical set of interdependencies for the firm.

\section{Outcome Control Power and the Allocation of Performance Outcomes}

The second proposition, which specified the relationship between the degree of outcome control power of each interest group and their respective long-term outcomes, was tested in two steps. First, based on the outcome interdependencies presented in Table 2, the outcome control powers of different constituencies were calculated and the interrelationships among them examined. In the second step, the relationships between outcome control powers and the long-term outcomes received by the four constituencies were investigated.

Table 4 shows the correlations among the four constituencies in terms of the three different measures of outcome control. The results provide support for both the agency and the constituency perspectives in an interesting way. As the agency theory predicts, the aggregate outcome control powers of residual claimants and bondholders are positively correlated, indicating that there exists a strong positive relationship between the outcome control powers of these two constituencies. None of the other correlations are significant in this group. Furthermore, the aggregate outcome dependency among different constituencies is significantly correlated only in the case of customers and short-term interest groups. This result shows that they are equally influenced by all the other constituencies' outcome control. The last set of correlations among the net outcome control powers of different constituencies provides support for the constituency perspective. They indicate that power distribution is competitive and that increase in one interest group's net outcome control power results in a decrease in the others' net power. Here again, the competitive power relationship among constituencies is not between residual claimants and bondholders, or between customers and short-term interest groups, but between the two major groups of constituencies identified in Table 3.

The results in Table 5 present some striking differences between the two major groups of constituencies with regard to the relationship between their outcome

Table 4

Correlations Between Constituencies' Aggregate Outcome Control Powers, Aggregate Outcome Dependency, and Net Outcome Control Powers

$(N=10)$

\begin{tabular}{|c|c|c|c|c|c|c|c|c|c|c|c|c|}
\hline & \multicolumn{4}{|c|}{$\begin{array}{c}\text { Aggregate } \\
\text { Outcome Control }\end{array}$} & \multicolumn{4}{|c|}{$\begin{array}{c}\text { Aggregate Outcome } \\
\text { Dependency }\end{array}$} & \multicolumn{4}{|c|}{$\begin{array}{c}\text { Net } \\
\text { Outcome Control } \\
\end{array}$} \\
\hline & 1 & 2 & 3 & 4 & 1 & $\underline{2}$ & 3 & 4 & 1 & 2 & 3 & 4 \\
\hline $\begin{array}{l}\text { Residual } \\
\text { claimants (1) }\end{array}$ & 1.00 & -.32 & $.73 * *$ & -.05 & $\overline{1.00}$ & $\overline{-.42}$ & .06 & -.16 & $\overline{1.00}$ & $-.92 * *$ & .28 & -.22 \\
\hline Customers (2) & & 1.00 & -.33 & -.38 & & 1.00 & .24 & $.55^{*}$ & & 1.00 & -.49 & .10 \\
\hline Bondholders (3) & & & 1.00 & -.38 & & & 1.00 & .15 & & & 1.00 & $-.55^{*}$ \\
\hline $\begin{array}{l}\text { Short-term } \\
\text { interest (4) }\end{array}$ & & & & 1.00 & & & & 1.00 & & & & 1.00 \\
\hline
\end{tabular}


Table 5

The Relationships between the Constituencies' Outcomes and the Three Aggregate Measures of Outcome Control Power $(N=10)$

\begin{tabular}{|c|c|c|c|c|}
\hline \multirow[b]{2}{*}{$\begin{array}{l}\text { Measures of Outcome } \\
\text { Control Power }\end{array}$} & \multirow[b]{2}{*}{$\begin{array}{l}\text { Residual } \\
\text { Claimants }\end{array}$} & \multicolumn{2}{|c|}{ Long-term Average Outcomes } & \multirow[b]{2}{*}{$\begin{array}{c}\text { Short-term } \\
\text { Interest }\end{array}$} \\
\hline & & Customers & Bondholders & \\
\hline $\begin{array}{l}\text { Aggregate Outcome } \\
\text { Control Power }\end{array}$ & $.57 *$ & -.10 & $.47^{*}$ & .25 \\
\hline $\begin{array}{l}\text { Aggregate Outcome } \\
\text { Dependency }\end{array}$ & -.10 & $.52 *$ & .23 & $\begin{array}{l}.83 * * \\
(.001)\end{array}$ \\
\hline $\begin{array}{l}\text { Net Outcome Control } \\
\text { Power }\end{array}$ & .30 & -.22 & .25 & $\begin{array}{l}-.68 * * \\
(.01)\end{array}$ \\
\hline
\end{tabular}

${ }^{*} p<.05 .{ }^{* *} p<.01$.

control powers and long-term outcomes. For residual claimants and bondholders, their long-term average outcomes are positively correlated to their aggregate outcome control powers. Given the symbiotic power relations between them, it is possible to state that both parties gain; that is, their long-term average outcomes increase, as long as any one of them has greater outcome control power. For customers and short-term interests, however, the relationship is reversed. Their longterm average outcomes increase when their aggregate outcome dependency increases. The critical implication of these relations is that the competitive outcome interdependency between the two groups identified in Table 4 (column 3) can be converted into a stable symbiotic interdependency only if this reverse relationship exists. This is the only way in which all the parties gain or lose at the same time and the conflict of interest is converted into a symbiotic outcome interdependency.

\section{Discussion and Implications}

The results of this investigation indicate that agency and constituency frameworks developed in finance and organization theory are not contradictory but complementary. The source of this complementarity is due to not only the empirical findings presented in this article but also to the fundamental question asked by these alternative perspectives. Whether an organization is viewed as a set of contracts among the factors of production or as a coalition of interest groups, both perspectives ask basically the same question: When each member of the coalition or of the factors of production is motivated by self-interest, how is it possible that the organization survives and, more important, exists as an efficient form of economic association (Fama, 1980)?

Even though each framework attempts to answer this question within its own theoretical logic, in the final analysis the perspectives do converge. For instance, agency theory argues that the relationship between shareholders and bondholders may lead to agency problems. Such agency problems are resolved, however, because even though each party acts in its own self-interest, all parties realize that their destinies depend to some extent on the survival of the firm as a whole in its competition with other firms in the market (Alchian \& Demsetz, 1972; Jensen \& 
Meckling, 1976). In other words, the competitive outcome interdependency is converted into symbiotic interdependency.

Within the constituency framework, the same question is answered by concentrating on the resource interdependencies among interest groups representing the organization. The conflict of interest is converted into a symbiotic interdependence by manipulating how outcomes are achieved and allocated as well as by manipulating which outcomes are desired by the members of the coalition.

As the results presented in Tables 4 and 5 show, conflicting outcome control powers of different interest groups are converted into symbiotic outcome interdependencies as a result of stable patterns of interactions between the nature of interdependencies and the outcomes allocated to the constituencies. Given the comparative nature of this study, it is possible to argue that the needed conversion from competitive to symbiotic interdependency is built into the system of interactions among the four interest groups identified in the investigation.

One basic implication of these findings and the alternative perspectives discussed earlier is that a new description of the managerial role, not only in theory but also in practice, is necessary. Both the agency and the constituency perspectives implicitly or explicitly argue that the view of managers as agents of a specific class of principals, namely shareholders, is no longer a valid argument. Whether managers are conceived as those who represent yet another factor of production or as those who establish negotiated environments favorable to the organization, they are agents without principals, but with constituencies. Their role is to sustain the belief that future interdependencies are likely to endure, and that the organization as a nexus of contracts among interest groups is likely to survive because the destinies of coalition members depend to some extent on the survival of the coalition itself.

Similar interpretations of the symbolic nature of the managerial role have also been expressed recently in the legal literature, specifically in relation to contract law (MacNeil, 1980). As agents of contractual relations, managers mostly deal with multiple constituencies, including those of which they themselves are members. To define the manager as an agent who owes reasonable effort and unswerving loyalty to a specific class of principals becomes logically impossible under these conditions. In a world without principals, contractual solidarity is not a byproduct of discrete contracts among a group of self-interested parties, but a byproduct of the common belief in effective future interdependencies and their stability. In MacNeil's (1980, p. 92) terms, each party in the coalition must give an affirmative answer to the following question: "Do I think the conditions will continue to exist whereby each of us will desire and be able to depend on the other?"

The creation of such an organic contractual solidarity among the members of a coalition representing the organization emphasizes the symbolic role managers must play. In other words, from a practical point of view, their role is not to find ways to reduce the existing interdependencies among contituencies but to sustain these outcome interdependencies. They need to convince the constituencies of their organization that the situation is not a zero-sum game but a mix-motive situation, and that as long as the existing interdependencies are maintained, all will gain from the coalition. 


\section{Appendix}

Means and Standard Deviations of the Variables in Tables 3, 4, and 5

$$
(N=10)
$$

\begin{tabular}{lrr}
\hline \hline Variables & \multicolumn{1}{c}{$M$} & \multicolumn{1}{c}{$S D$} \\
\hline Long-term Average Outcomes & & \\
$\quad$ Residual Claimants & 9.071 & 7.396 \\
Customers & 137.300 & 17.346 \\
$\quad$ Bondholders & 41.270 & 5.725 \\
$\quad 1.496$ & 0.320 \\
Short-term Interests & & \\
Aggregate Outcome Control & 0.732 & 0.575 \\
$\quad$ Residual Claimants & 1.219 & 1.469 \\
Customers & 0.821 & 0.792 \\
$\quad$ Bondholders & 0.478 & 0.477 \\
Short-term Interests & & \\
Aggregate Outcome Dependency & 1.253 & 1.306 \\
$\quad$ Residual Claimants & 0.759 & 0.449 \\
Customers & 0.658 & 0.552 \\
Bondholders & 0.579 & 0.639 \\
Short-term Interests & & \\
Net Outcome Control & -0.521 & 1.547 \\
$\quad$ Residual Claimants & 0.459 & 1.753 \\
Customers & 0.163 & 0.759 \\
$\quad$ Bondholders & -0.101 & 0.595 \\
\hline Short-term Interests & & \\
\hline
\end{tabular}

\section{References}

Ackoff, R.L. (1970). A concept of corporate planning. New York: Wiley.

Aharoni, Y., Maimon, Z., \& Seger, E. (1978). Performance and autonomy in organizations: Determining dominant environmental components. Management Science, 24(9), 949-959.

Alchian, A.A., \& Demsetz, H. (1972). Production, information costs and economic organization. American Economic Review, 62, 777-795.

Baumol, J. (1959). Business behavior, value and growth. New York: Macmillan.

Berle, A., \& Means, G.C. (1932). The modern corporation and private property. New York: Macmillan.

Cheng, H., \& Skimenda, T.A. (1981). An empirical analysis of useful financial ratios. Financial Management, 10, 51-60.

Cyert, M., \& March, J.C. (1963). A behavioral theory of the firm. Englewood Cliffs, NJ: PrenticeHall.

Fama, E.F. (1980). Agency problems and the theory of the firm. Journal of Political Economy, 88, 288-307.

Fama, E.F., \& Jensen, M.C. (1983). Separation of ownership and control. Journal of Law and Economics, 26, 301-325.

Freeman, E.R. (1984). Strategic management: A stakeholders approach. Boston, MA: Pitman.

Friedlander, F., \& Pickle, H. (1968). Components of effectiveness in small organizations. Administrative Science Quarterly, 13, 289-304.

Gupta, M.C., \& Huefner, R.J. (1972). A cluster analysis study of financial ratios and industry characteristics. Journal of Accounting Research, 10, 77-95.

Holl, P. (1975). Effects of control type on performance of the firm in the U.K. Journal of Industrial Economics, 23, 257-271.

Hurdle, G.J. (1974). Leverage, risk, market structure and profitability. Review of Economics and Statistics, 56, 478-485. 
Jensen, M.C., \& Meckling, W.H. (1976). Theory of the firm: Managerial behavior, agency costs, and ownership structure. Journal of Financial Economics, 3, 305-360.

Kamerschen, D.R. (1968). The influence of ownership and control on profit rates. American Economic Review, 58, 432-447.

Lev, B. (1974). Financial statement analysis: A new approach. Englewood Cliffs, NJ: PrenticeHall.

MacNeil, I.R. (1980). The new social contract: An inquiry into modern contractual relations. New Haven, CT: Yale University Press.

McKean, J.R., \& Kania, J.J. (1978). An industry approach to owner-manager control and profit performance. Journal of Business, 51, 327-342.

Martin, S. (1976). Advertising, concentration, and profitability: The simultaneity problem. The Bell Journal of Economics, 7, 639-647.

Palmer, J. (1973). The profit-performance effects of the separation of ownership from control in large U.S. industrial corporations. The Bell Journal of Economics, 4, 293-303.

Pate, J.L. (1969). Joint venture activity, 1960-1968. Economic Review [Federal Reserve Bank of Cleveland], (1), 16-23.

Pfeffer, J. (1972). Merger as a response to organizational interdependence. Administrative Science Quarterly, 17, 382-394.

Pfeffer, J. (1978). Organizational design. Arlington Heights, IL: AHM.

Pfeffer, J., \& Salancik, G.R. (1978). The external control of organizations. New York: Harper \& Row.

Pinches, G.E., Eubank, A.A., Mingo, K.A., \& Caruthers, J.K. (1975). The hierarchical classification of financial ratios. Journal of Business Research, 3, 295-310.

Pinches, G.E., Mingo, K.A., \& Caruthers, J.K. (1973). The stability of financial patterns in industrial organizations. Journal of Finance, 28, 389-396.

Porter, M.E. (1980). Competitive strategy. New York: Free Press.

Schendel, D., \& Patton, G.R. (1978). A simultaneous equation model of corporate strategy. Management Science, 24, 1611-1621.

Simon, H.A. (1959). Theories of decision making in economics and behavioral science. American Economic Review, 49, 253-283.

Sorenson, R. (1974). The separation of ownership and control and firm performance: An empirical analysis. Southern Economic Journal, 41, 145-149.

Trostel, A.O., \& Nichols, M.L. (1982). Privately-held and publicly-held companies: A comparison of strategic choices and management processes. Academy of Management Journal, 25, 4562.

Ware, R.F. (1975). Performance of manager versus owner controlled firms in the food and beverage industry. Quarterly Review of Economics and Business, 15, 81-92.

Huseyin Leblebici is an associate professor in the Department of Business Administration at the University of Illinois.

Avi Fiegenbaum is an assistant professor of corporate strategy in the School of Business Administration at The University of Michigan. 